Sharif University of Technology
Scientia Iranica
SCIENTIA
IRAN I CA
http://scientiairanica.sharif.edu

\title{
The estimation of flood quantiles in ungauged sites using teaching-learning based optimization and artificial bee colony algorithms
}

\author{
T. Anılan*, E. Uzlu, M. Kankal, and Ö. Yüksek \\ Department of Civil Engineering, Faculty of Engineering, Karadeniz Technical University, 61080 Trabzon, Turkey. \\ Received 29 February 2016; accepted 12 November 2016
}

\author{
KEYWORDS \\ Regional flood \\ frequency analysis; \\ L-moments; \\ Teaching-learning \\ based optimization; \\ Artificial bee colony \\ algorithm; \\ Turkey.
}

\begin{abstract}
In this study, a Regional Flood Frequency Analysis (RFFA) was applied to 33 stream gauging stations in the Eastern Black Sea Basin, Turkey. Homogeneity of the region was determined by discordancy $\left(D_{i}\right)$ and heterogeneity measures $\left(H_{i}\right)$ based on L-moments. Generalized extreme-value, lognormal, Pearson type III, and generalized logistic distributions were fitted to the flood data of the homogeneous region. Based on the appropriate distribution for the region, flood quantiles were estimated for return periods of $T=5,10,25,50,100$, and 500 years. A non-linear regression model was then developed to determine the relationship between flood discharges and meteorological and hydrological characteristics of the catchment. In order to compare regression analysis with other models, Artificial Bee Colony algorithm (ABC) and Teaching-Learning Based Optimization (TLBO) models were developed. The equations were obtained using the $\mathrm{ABC}$ and TLBO algorithms to estimate flood discharges for different return periods. The analysis showed that the TLBO and ABC results were superior to the regression analysis. Error values indicated that the TLBO method yielded better results for the estimation of flood quantiles for different independent variables.
\end{abstract}

(C) 2018 Sharif University of Technology. All rights reserved.

\section{Introduction}

Reliable estimation of flood discharges has great importance in the planning, design, and management of hydraulic structures. Regional Flood Frequency Analysis (RFFA) enables estimation of flood magnitudes in different return periods at any stream location where stream flow data are quite limited or completely absent. Thus, RFFA is frequently used to obtain design flood estimates.

\footnotetext{
*. Corresponding author. Tel.: +90 462 3772654;

Fax: +90 462 3772606

E-mail addresses: koctugce@gmail.com (T. Anılan);

ergunuzlu@hotmail.com (E.Uzlu); mkankal06@gmail.com (M. Kankal);yuksek@ktu.edu.tr (Ö. Yüksek).
}

doi: $10.24200 /$ sci.2017.4185
Identification of homogeneous regions, selection of appropriate regional frequency distribution, and estimation of flood quantiles at sites of interest are the basic concepts of RFFA. Many RFFA methods have been developed up to now. Some of the most commonly adopted RFFA methods in practice include (i) the rational method, (ii) index flood procedures with probability weighted moments and L-moments, and (iii) regression and artificial intelligence based methods [1]. As an example of rational method, Jiapeng et al. [2] proposed formulas that are modifications of the traditional rational formula and able to calculate the flood design peak discharges. The use of the index flood procedure started with Wallis [3], who used it in conjunction with probability weighted moments and the Wakeby (WAK) distribution as a method of estimating quantiles in the frequency distribution. Probability 
weighted moments were found to perform well for other distributions, but were hard to interpret [4]. Hosking [5] found that certain linear combinations of probability weighted moments, which he called the "L-moments", have some theoretical advantages over conventional moments of being able to characterize wider range of distributions.

So far, a variety of L-moments based methods have been extensively investigated in RFFA across the world to obtain more reliable estimates. Rao et al. [6] analyzed maximum flow data from 93 sites in the Wabash River, USA, using L-moments, and concluded that Generalized-Extreme Value (GEV) distribution appeared to be more robust to the region. Parida et al. [7] performed a regional flood frequency analysis on Mahi-Sabarmati basin in India using the L-moments and index flood procedure. They modeled floods in the region using the Lognormal (LN) distribution as the appropriate distribution. Adamowski [8] studied probability density functions for floods in the Provinces of Ontario and Quebec, Canada. In Turkey, Haktanir [9], Sorman and Okur [10], Atiem and Harmancioglu [11], Saf [12], and Bayazit and Onoz [13] carried out Lmoments based RFFA. In recent years, Seckin et al. (2011) showed that GEV and WAK distributions, whose parameters are computed by the L-moments method, are adequate in predicting quantile estimates in Turkey. Seckin et al. [14] then enhanced their Lmoments based study with artificial intelligence techniques to predict flood peaks of various return periods at ungauged sites in that basin in Turkey. It was concluded that the Multi-Layer Perceptrons (MLP) model is observed to ensure estimates close to the L-moments approach. Aydogan et al. [15] applied a RFFA to Coruh Basin by L-moments method in Turkey. They estimated flood quantiles and compared them with those estimated previously by an at-site frequency analysis (Gumbel distribution) on the basin master plan for four large dams in the Coruh Basin. Firat et al. [16] also calculated flood discharges for Turkey using distribution function parameters and observed higher error values with the increase of recurrence period.

The spatial variations in flow statistics are closely related with the variations in regional physiographical and meteorological factors. Quantile Regression (QR) models are often used to make estimates of flow statistics for ungauged sites and their relationships between catchment properties $[17,18]$. Ouarda et al. [19] applied the Canonical Correlation Analysis (CCA) technique to a dataset of 106 stations from the province of Ontario, Canada, and presented its usefulness in RFFA. Jingyi and Hall [20] performed Residuals method, Ward's cluster method, the fuzzy c-means method, and Kohonen neural network on 86 sites in the Gan River Basin and the Ming River Basin in China to identify homogeneous regions based on site characteristics; they also examined the discordancy and homogeneity of the groups by L-moments of the distribution of annual floods. Reis et al. [21] introduced a Bayesian analysis of the Generalized Least Squares (GLS) model, which provides measures of the model error variance that are more accurate. Many studies with regression-based techniques [22-31] have been used to describe quantitative relationships between independent and dependent variables.

As an alternative to these methods, artificial intelligence methods can be applied to RFFA by combining several methods [32]. Dawson et al. [33] used Artificial Neural Networks (ANN) model for RFFA, and concluded that ANN provided more accurate flood quantile estimates than the traditional regression techniques. Shu and Ouarda [34] integrated CCA and ANN for flood quantile estimation at ungauged sites in Quebec, Canada. They concluded that the proposed CCA-based ANN models presented better performance than the original ANN models. Shu and Ouarda [35] provided a general framework named as Adaptive Neuro-Fuzzy Inference System (ANFIS) with combining two techniques, i.e. ANN and fuzzy systems. Their study revealed that the ANFIS model provided an integrated mechanism for identifying the hydrological regions and flood estimates with nonlinear modeling capability. Aziz et al. [36] compared the performances of the ANN-based RFFA model with classical regression techniques, and indicated that ANN presented the best performing RFFA model. Seckin et al. [14] applied ANN models to compare them with multiple regression ones. They found that the performance of the ANN-MLP model is superior to the others.

With the increase in the application of artificial intelligence techniques in hydrology, optimization techniques have also been frequently used in this area in recent years. Chau [37] used Particle Swarm Optimization training algorithm (PSO) to predict water levels in Shing Mun River of Hong Kong with different lead times based on the upstream gauging stations or stage/time history at the specific station. It was shown that the PSO technique could act as an alternative training algorithm for ANNs. Jiong-feng and Wanchang [38] applied Genetic Algorithm model (GA) to the daily rainfall-runoff simulations, and indicated that the proposed approach was feasible and of high computational efficiency and could be transferred to model parameter calibrations for conceptual hydrological models in the similar categories. Jun et al. [39] proposed an Ant Colony Optimization-based (ACO) support vector machine algorithm SVM model (ACOSVM) to optimize the parameters using an ACO random-seeking strategy. It was concluded that ACOSVM is much more efficient in global optimization and its forecasting accuracy is better than that of the con- 
ventional parameter-choosing method. Kisi et al. [40] investigated Artificial Bee Colony algorithm (ABC) for modeling discharge-suspended sediment relationship and compared the model with neural differential evolution, adaptive neuro-fuzzy, neural networks, and rating curve models. They concluded that the ANN-ABC was able to produce better results than the other models. ANN-ABC model was used by Salimi et al. [41] to predict the average weekly discharge of Tang-e Karzin station, Iran, through the discharge information. It was observed that applying ABC to ANN could improve the estimations of the network outputs. Uzlu et al. [42] applied ABC and a recently developed advanced optimization algorithm, Teaching-Learning Based Optimization (TLBO), to the regression functions of the data for the estimation of the berm parameters in understanding sediment movements. Although these optimization techniques have been applied to a wide range of hydrological and hydraulics problems, such as rainfall runoff modeling, hydrologic forecasting, and coastal engineering, there is not any in RFFA with the ABC and TLBO. Therefore, this study will be the first to use the ABC and TLBO algorithms in a RFFA.

The object of the study is to compare the traditional Regression Analysis (RA) with the ANN-based algorithms of ABC and TLBO using both physical and meteorological characteristics of the Eastern Black Sea Basin (EBSB), Turkey. This study examines the applicability of the algorithms to RFFA using an extensive and elaborated data. In accordance with this purpose, L-moments method is also used for the estimation of flood quantiles, and regression models are developed for the selection of independent variables. An overview of L-moments, ABC, and TLBO methods is presented in Section 3. Model development is also presented in this section. Section 4 presents the details of the RFFA with ABC and TLBO. In Section 5, the results obtained by applying the proposed approaches are presented and discussed. Finally, in Section 6, the conclusions are presented.

\section{The study area and data description}

With respect to its river streamflow, Turkey is divided into 26 basins [43]. Among them, the Black Sea Coast receives rainfall all the year round and also the greatest amount of rainfall in Turkey [44]. The EBSB is located on the northeastern coast of Turkey (Figure 1). The basin is surrounded by the Eastern Black Sea Mountains on the south and the Black Sea on the north. It averages nearly $1,100 \mathrm{~mm}$ annually; this figure can reach 2,300 $\mathrm{mm}$ near Rize Province. This region was selected as the study area since it has a great potential risk against floods due to its meteorological and topographic characteristics. Devastating flood events have occurred in the EBSB, especially in recent years. In this region, nearly 50 destructive floods have taken place between the years 1955 and 2010, causing 258 deaths and nearly US $\$ 500,000,000$ of damage [44]. Therefore, reliable estimation of peak discharges is essential for the design of hydraulic structures and also for flood risk management.

Two types of data were used in this study: (i) streamflow data (the annual maximum flood data) for RFFA and estimation of flood quantiles and (ii) physiographical, meteorological, and hydrological data for regression analysis techniques. The annual maximum flood data of 33 Stream-Gauging Stations (SGS) used in the study were obtained from both General Directorate of State Hydraulic works (DSI) and General Directorate of Electrical Power Resources and Development Administration (EIE). The locations of the stations used are shown in Figure 1. The longer the period of the record is, the more accurate

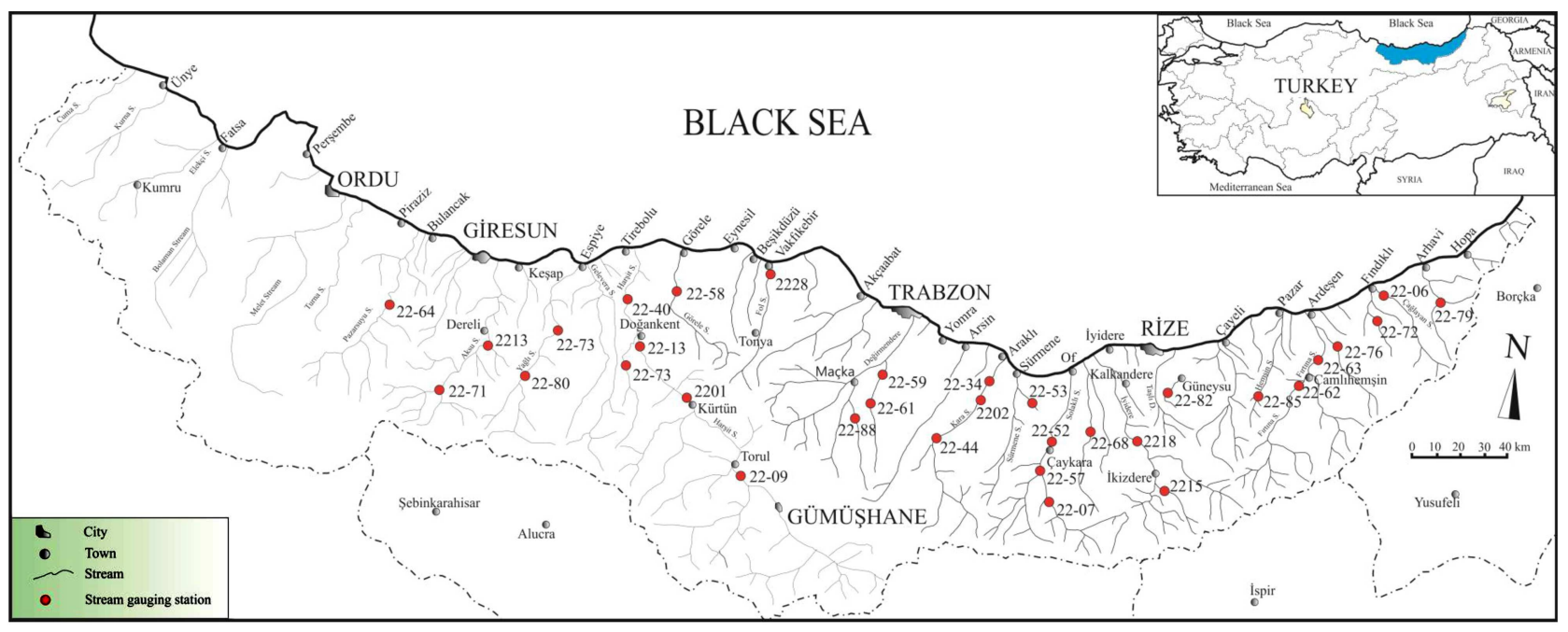

Figure 1. Location map of EBSB and studied area. 
and representative statistical results will be in RFFA. Therefore, a minimum of ten years of SGSs were selected for the quality of the estimates. Record lengths of the selected 33 SGSs range 10-42 years (mean: 28 years). Flood quantiles of these stations were estimated for the selected return periods $T=5,10,25,50,100$, and 500 years $\left(Q_{5}, Q_{10}, Q_{25}, Q_{50}, Q_{100}\right.$, and $\left.Q_{500}\right)$ by fitting the best distribution with the region.

The selection of independent variables is a critical point in the estimation of flood discharges since they are influenced by both physical and meteorological factors. Previous RA in RFFA studies was examined for the selection of independent variables. It was determined that most of them adapted drainage area $(A)$, main stream slope $(S)$, mean annual rainfall $(R)$, stream density $(D)$, and elevation $(E)$ to RA, as presented in Table 1 . Therefore, these variables were included in this study. Rainfall intensity $(I)$ was also used in this study as an independent variable, since it is known as an important meteorological parameter to affect the floods. However, there are few studies to include rainfall intensity in RA for RFFA $[29,36]$.

The annual greatest precipitation values $(\mathrm{mm})$ observed in various standard times, measured in ten meteorological stations in the region and obtained from Turkish State Meteorological Service (DMI), were used to calculate the rainfall intensities $(I)$ [45]. Rainfall intensities were calculated by Aziz et al. [36] for various return periods with duration equal to time of concentration (in hours):

$$
t_{c}=0.76 A^{0.38}
$$

where $A$ is basin area $\left(\mathrm{km}^{2}\right)$. The rainfall parameters for each SGS were calculated by Thiessen Polygons method. EASYFIT goodness of fit procedure was adapted to rainfall intensities to determine the most appropriate distribution of the region. Then, using the

Table 1. Catchment characteristics of independent variables used in some previous studies.

\begin{tabular}{|c|c|c|c|}
\hline Authors & Country & Method & Independent variables adopted \\
\hline Jingyi and Hall (2004) [20] & China & $\begin{array}{l}\text { Index flood } \\
\text { and ANN }\end{array}$ & $\begin{array}{l}A, R, S, E \text {, main stream length, geological } \\
\text { feature index, plantation cover index }\end{array}$ \\
\hline Shu and Burn (2004) [32] & England, UK & QR and ANN & $A, R$, soil drainage type \\
\hline Dawson et al. (2006) [33] & Ireland & RA and ANN & $\begin{array}{l}A, R, S, E \text {, base flow index, standard } \\
\text { percentage run-off, longest drainage path }\end{array}$ \\
\hline Leclerc et al. (2007) [24] & Canada & $\mathrm{CCA}$ & $\begin{array}{l}A, R \text {, gauging station latitude, gauging station } \\
\text { longitude, mean air temperature }\end{array}$ \\
\hline $\begin{array}{l}\text { Shu and Ouarda } \\
(2007,2008)[34,35]\end{array}$ & Canada & $\begin{array}{l}\text { CCA, ANN } \\
\text { and ANFIS }\end{array}$ & $\begin{array}{l}A, R, S \text {, fraction of the basin area covered with } \\
\text { lakes, annual mean air temperature }\end{array}$ \\
\hline $\begin{array}{l}\text { Palmen and Weeks } \\
\qquad \text { (2011) [26] }\end{array}$ & Australia & QR & $\begin{array}{l}A, R, S, I, D \text {, river length, sediment area, } \\
\text { plantation area, evapotranspiration }\end{array}$ \\
\hline Malekinezhad et al. (2011) [28] & Iran & $\begin{array}{l}\text { Index flood } \\
\text { and RA }\end{array}$ & $\begin{array}{l}R \text {, Length of main waterway, compactness } \\
\text { coefficient, mean annual temperature }\end{array}$ \\
\hline Haddad et al. (2012) [29] & Australia & QR and RA & $A, R, I, D$, mean annual evapotranspiration \\
\hline Aziz et al. (2013) [36] & Australia & QR and ANN & $A, R, S, I$, evapotranspiration \\
\hline Seckin et al. (2013) [14] & Turkey & RA and ANN & $A, E$, latitude, longitude, return period \\
\hline This study (2014) & Turkey & $\begin{array}{l}\mathrm{RA}, \mathrm{ABC} \text { and } \\
\mathrm{TLBO}\end{array}$ & $A, R, S, E, D, I$ \\
\hline
\end{tabular}


Table 2. Exploratory data analysis of the independent variables.

\begin{tabular}{lccc}
\hline Independent variables & Range & Mean & SD \\
\hline Drainage area, $A\left(\mathrm{~km}^{2}\right)$ & $83.3-3132.8$ & 514.49 & 711.08 \\
Main stream slope, $S(\mathrm{~m} / \mathrm{km})$ & $0.22-0.333$ & 0.06 & 0.05 \\
Elevation, $E(\mathrm{~m})$ & $17-1150$ & 433.24 & 309.81 \\
Stream density, $D\left(\mathrm{~km} / \mathrm{km}^{2}\right)$ & $167.2-446.3$ & 264.22 & 59.24 \\
Mean annual rainfall, $R(\mathrm{~mm})$ & $471.87-2330.81$ & 1105.04 & 489.99 \\
Rainfall intensity $I_{5}$ & $1.67-19.33$ & 9.5 & 5.44 \\
Rainfall intensity $I_{10}$ & $1.95-22.55$ & 11.2 & 6.41 \\
Rainfall intensity $I_{20}$ & $2.3-27.01$ & 13.53 & 7.81 \\
Rainfall intensity $I_{50}$ & $2.57-31.52$ & 15.38 & 9.01 \\
Rainfall intensity $I_{100}$ & $2.83-37.29$ & 17.44 & 10.38 \\
Rainfall intensity $I_{500}$ & $3.45-55.06$ & 22.85 & 14.41 \\
\hline
\end{tabular}

most appropriate distribution, rainfall intensity values were calculated for $T=5,10,25,50,100$, and 500 years return periods $\left(I_{5}, I_{10}, I_{25}, I_{50}, I_{100}\right.$, and $\left.I_{500}\right)$. Drainage areas of SGS, ranging from 83.3 to 3,132 $\mathrm{km}^{2}$ (mean: $774.83 \mathrm{~km}^{2}$ ), and elevations, ranging 17 to $1,150 \mathrm{~m}$ (mean: $433.24 \mathrm{~m}$ ), were obtained from DSI and EIE [46]. Mainstream slopes and stream density values were compiled from Saka [47].

In summary, the independent variables used in this study are: drainage area, $A\left(\mathrm{~km}^{2}\right)$, main stream slope, $S(\mathrm{~m} / \mathrm{km})$, elevation, $E(\mathrm{~m})$, stream density, $D$ $\left(\mathrm{km} / \mathrm{km}^{2}\right)$, mean annual rainfall, $R(\mathrm{~mm})$, and rainfall, intensities, $I(\mathrm{~mm} / \mathrm{h})$ for $T=5,10,25,50,100$, and 500 years. Ranges and summary statistics of these data are presented in Table 2 .

\section{Methodology}

\subsection{Estimation of flood quantiles}

In all stages of RFFA, the identification of homogeneous regions has great significance. It is expected that the more homogeneous a region is, the more accurate the estimation will be in RFFA based on L-moments method [48]. The efficiency of the regionalization is relatively dependent on the historical flow record length and the similarity of the hydrological characteristics of regions [49]. After identifying a homogeneous region, an appropriate distribution needs to be selected for the regional frequency analysis. Assessment of the goodness of different candidate distributions for a particular application will largely be based on how well the distributions fit the available data. When several distributions fit the data sufficiently, the best choice among them will be the distribution that is most robust [50].

In this study, homogeneity of the region was determined by discordancy $\left(D_{i}\right)$ and heterogeneity measures $\left(H_{i}\right)$ based on L-moments. The probability distributions, whose parameters were computed by the
L-moments method, were Generalized Logistic (GLO), $\mathrm{GEV}, \mathrm{PE} 3$, and LN distributions in the analysis $Z^{\mathrm{DIST}}$ statistics used for the goodness of fit for each of 33 stations.

The fundamental quantity of statistical frequency analysis is the frequency distribution, which specifies how frequently the possible values of $Q$ occur. The probability that the actual value of $Q$ is at most $x$ is denoted by $F(x)$ :

$$
F(x)=\operatorname{Pr}[Q \leq x] .
$$

$F(x)$ is the cumulative distribution function of the frequency distribution. Its inverse function, $x(F)$, the quantile function of the frequency distribution, expresses the magnitude of an event in terms of its nonexceedance probability $F$. The quantile of return period $T, Q_{T}$, is an event magnitude so extreme that it has probability $1 / T$ of being exceeded by any single event. For an extreme high event, in the upper tail of the frequency distribution, $Q_{T}$ is given by:

$$
F(Q(T))=\left(1-\frac{1}{T}\right)
$$

for an extreme low event, in the lower tail of the frequency distribution, the corresponding relations are $Q_{T}=x(1 / T)$ and $F\left(Q_{T}\right)=1 / T$. The goal of the frequency analysis is to obtain a useful estimate of quantile $Q_{T}$ for a return period of scientific relevance [51]. $Q_{T}$ functions of the best-fit distribution were used for the estimation of quantiles related to $T$ values of $5,10,25,50,100$, and 500 years.

\subsection{Selection of independent variables}

Regression analysis was applied to the data to get a set of variables that provides the best statistical model. 16 models expected to be significant were developed for six variables. Drainage area and rainfall intensity were 
Table 3. Models and independent variables used in the study.

\begin{tabular}{cccl}
\hline $\begin{array}{c}\text { Model } \\
\text { no }\end{array}$ & $\begin{array}{c}\text { Independent } \\
\text { variables }\end{array}$ & $\begin{array}{c}\text { Model } \\
\text { no }\end{array}$ & $\begin{array}{c}\text { Independent } \\
\text { variables }\end{array}$ \\
\hline 1 & $A, I_{\text {tc-ARI }}$ & 9 & $A, I_{\text {tc-ARI }}, S, E$ \\
2 & $A, I_{\text {tc-ARI }}, D$ & 10 & $A, I_{\text {tc-ARI }}, S, R$ \\
3 & $A, I_{\text {tc-ARI }}, S$ & 11 & $A, I_{\text {tc-ARI }}, E, R$ \\
4 & $A, I_{\text {tc-ARI }}, E$ & 12 & $A, I_{\text {tc-ARI }}, D, S, E$ \\
5 & $A, I_{\text {tc-ARI }}, R$ & 13 & $A, I_{\text {tc-ARI }}, D, S, R$ \\
6 & $A, I_{\text {tc-ARI }}, D, S$ & 14 & $A, I_{\text {tc-ARI }}, D, E, R$ \\
7 & $A, I_{\text {tc-ARI }}, D, E$ & 15 & $A, I_{\text {tc-ARI }}, S, E, R$ \\
8 & $A, I_{\text {tc-ARI }}, D, R$ & 16 & $A, I_{\text {tc-ARI }}, D, S, E, R$ \\
\hline
\end{tabular}

found to be the most important predictor variables in the previous RFFA studies [36]. These models, which contain drainage area, rainfall intensity, and combinations of the other four-predictor variables, are shown in Table 3 . The pre-calculated discharges for $T=5,10,25,50,100$, and 500 years return periods were then adapted to the independent variables using a regression model. Regression analysis was applied to the data for the determination of discharges as a function of the catchment characteristics having the highest determination coefficient $\left(R^{2}\right)$. In this analysis, each return period of discharges corresponds to the rainfall intensities with the same return periods.

Model 16 represents the best $R^{2}$ values, and indicates that drainage area, stream frequency, stream slope, elevation, average annual rainfall, and rainfall intensity are significant variables that greatly influence the discharges. Further details of the model results were discussed by Anilan [52].

\subsection{Artificial Bee Colony (ABC) algorithm}

The ABC algorithm is a new population-based metaheuristic approach proposed by Karaboga in [53]. The algorithm simulates the intelligent foraging behavior of honey bee swarms. In the $\mathrm{ABC}$ algorithm, the position of a food source represents a possible solution to the optimization problem and the nectar amount of a food source corresponds to the quality (fitness) of the associated solution. In this study, the unknown coefficients of regression functions are the parameters of a solution, and ABC algorithm tries to find optimum coefficients.

The ABC algorithm includes three control parameters: the number of food sources (SN), equal to the number of employed or onlooker bees; the "limit"; and the Maximum Cycle Number (MCN) [54]. The algorithm generates a randomly distributed initial population of SN solutions (for food source position) by Eq. (3) and also evaluates the amount of nectar (fitness) by Eq. (4):

$$
x_{i j}=x_{j}^{\min }+\operatorname{rand}(0,1)\left(x_{j}^{\max }-x_{j}^{\min }\right),
$$

$$
\text { fit }_{i}=\left\{\begin{array}{lll}
1 /\left(1+f_{i}\right) & \text { if } & f_{i} \geq 0 \\
1+a b s\left(f_{i}\right) & \text { if } & f_{i}<0
\end{array},,\right.
$$

where $i=1 \ldots \mathrm{SN} ; j=1 \ldots D$; SN denotes the number of food sources or employed bees; $D$ is the number of optimization parameters; $x_{j}^{\min }$ and $x_{j}^{\max }$ are the lower and upper bounds of the $j$ th parameter, respectively; $f_{i}$ is the value of the objective function. Each employed bee searches for new food sources with more nectar in the neighborhood of its current food source by Eq. (5). Then, it evaluates its nectar amount (fitness) by Eq. (4) [55]:

$$
v_{i j}=x_{i j}+\phi_{i j}\left(x_{i j}-x_{k j}\right) \text {, }
$$

where $k \in\{1,2, \ldots, \mathrm{SN}\}$ and $j \in\{1,2, \ldots, D\}$ are randomly chosen indices, and $k \neq i . \varphi_{i j}$ is a random real number within $[-1,1]$.

An onlooker bee chooses a food source depending on the probability values (Eq.(6)) calculated using the fitness value provided by the employed bees:

$$
p_{i}=\frac{\mathrm{fit}_{i}}{\sum_{i=1}^{\mathrm{SN}} \mathrm{fit}_{i}},
$$

when a food source cannot be improved in a predetermined number of trials (the "limit"), then food source is abandoned by the employed bee, which becomes a scout and seeks a new source without using experience [53]. A new food source position is generated randomly by Eq. (3), and the abandoned ones are replaced by scouts. The best food source is determined, and its position is memorized. This cycle is repeated until the requirements are met $[56,57]$.

\subsection{Teaching-Learning Based Optimization (TLBO) algorithm}

Rao et al. first developed a new meta-heuristic optimization algorithm based on the natural phenomenon of teaching and learning [58]. The TLBO algorithm has two common control parameters: the number of students (population size) and the stopping criterion (maximum number of iterations) [59]. Like other optimization algorithms, it uses a randomly generated initial population that consists of an even number of students, which are any solutions according to the population size and number of design variables in TLBO. These students consist of a number of design variables $\left(X_{i}\right)$ that generate an initial population as follows [60]:

$$
\begin{aligned}
& \text { for } i=1: P_{n} \\
& \text { for } j=1: n g \\
& \quad \text { randomly select any } X \text { between } \\
& \quad X_{\min } \text { and } X_{\max } \text { student }(i, j)=X \\
& \text { end for } \\
& \text { end for, }
\end{aligned}
$$

where $P_{n}$ is the population size, $n g$ is the number of 
groups if the design variables are categorized, $X_{\min }$ and $X_{\max }$ are the minimum and maximum values, respectively, of the design variables of the regression functions in this study.

In the TLBO algorithm, a new population is obtained as a result of two basic stages: the "teacher phase" or learning from the teacher, and the "learning phase," or trade of information between learners [61]. In the teacher phase, the student, with minimum objective function, $f$, in the entire population, is found and mimicked as a teacher. Other students in the current population are modified as the neighborhood of the teacher using the following equations:

$$
\begin{aligned}
& \text { student }_{i}=\left[X_{i, 1} X_{i, 2} \ldots X_{i}, D_{n}\right] \quad i=1,2, \ldots, P n \\
& \text { mean }=\left[\operatorname{mean}\left(X_{1}\right) \text { mean }\left(X_{2}\right) \ldots . \operatorname{mean}\left(X_{\mathrm{DN}}\right)\right] \\
& \text { student }_{\text {new }-t}=\text { student }_{i}+r^{*}\left(\text { teacher }-T F^{*} \text { mean }\right),
\end{aligned}
$$

where $\mathrm{DN}$ is the number of design variables, $P_{n}$ is the population size, $r$ is a random number varying in $[0,1]$, and $T F$ is the teaching factor ( 1 or 2 ). $X_{i}$ is the unknown coefficient of a regression function:

$$
T F=\text { round }(1+\operatorname{rand} *(2-1)) \text {. }
$$

The size of $r$ must be equal to that of the student for the scalar multiplication given in Eq. (7). The teaching phase is carried out with the hope of upgrading the students' level to teachers' [60]. In the learning phase, modified students increase their knowledge by interacting with each other according to the teaching-learning process [59].

At the end of the learning phase, a cycle (iteration) is completed for the TLBO algorithm. The learning and teaching phases are continued until the termination criterion is reached [59]. Uzlu et al. [42] presented detailed information about the TLBO algorithm and its implementation.

\section{Regional flood frequency analysis based on the ABC and TLBO algorithms}

In the prediction process, three regression functions, i.e. Linear Function (LF, Eq. (11)), Power Function (PF, Eq. (12)), and Exponential Function (EF, Eq. (13)), were used to estimate the regional flood frequency for the EBSB, Turkey. The general form of $\mathrm{LF}, \mathrm{PF}$, and EF can be expressed as follows:

$$
\begin{gathered}
y_{\text {linear }}=w_{0}+w_{1} x_{1}+w_{2} x_{2}+w_{3} x_{3} \\
+w_{4} x_{4}+\cdots+w_{n} x_{n}
\end{gathered}
$$

$$
\begin{gathered}
y_{\text {power }}=w_{0} x_{1}^{w_{1}} x_{2}^{w_{2}} x_{3}^{w_{3}} x_{4}^{w_{4}} \ldots x_{n}^{b_{n}} \\
y_{\text {exponential }}=w_{0}+\exp \left(w_{1}+w_{2} x_{1}+w_{3} x_{2}+w_{4} x_{3}\right. \\
\left.+w_{5} x_{4}+\cdots+w_{n+1} x_{n}\right)
\end{gathered}
$$

where $y$ is the dependent variable, $w_{i}$ s are the regression coefficients, and $x_{i}$ s are independent variables for general signification. In this study, $y$ corresponds to $Q$, and $x_{i}$ s are drainage area $(A)$, rainfall intensities $(I)$, stream density $(D)$, mean annual rainfall $(R)$, main stream slope $(S)$, elevation $(E)$, respectively.

Since the values of the independent variables are in extremely different ranges, optimization of the coefficients will become so difficult. This is because some values will be too big and some too small. Therefore, each group of input and output values is normalized into the range between $[0.1,0.9]$ in the $\mathrm{ABC}$ and TLBO models as follows:

$$
\begin{aligned}
\text { Normalized value }= & {\left[\frac{\text { Raw value }- \text { Min value }}{\text { Max value }- \text { Min value }}\right] } \\
& \times(0.9-0.1)+0.1
\end{aligned}
$$

The aim of estimating regional flood frequency is to find the fittest model to the observed data. The equations for six parameters were evaluated using 33 experimental data and the best equations with minimum SSE were determined. In addition, performances of $\mathrm{ABC}$ and TLBO models were compared using Mean Relative Error (MRE), Root Mean Square Error (RMSE), and Mean Absolute Error (MAE). MRE, RMSE, and MAE are calculated as follows:

$$
\begin{aligned}
& \mathrm{MRE}=\frac{1}{N} \sum_{i=1}^{N}\left|\frac{\operatorname{Ln}(Q)_{i_{\text {observed }}}-\operatorname{Ln}(Q)_{i_{\text {predicted }}}}{\operatorname{Ln}(Q)_{i_{\text {observed }}}}\right| \times 100 \\
& \text { RMSE }=\left[\frac{1}{N} \sum_{i=1}^{N}\left(\operatorname{Ln}(Q)_{i_{\text {observed }}}-\operatorname{Ln}(Q)_{i_{\text {predicted }}}\right)\right]_{(16)}^{1 / 2} \\
& \text { MAE }=\frac{1}{N} \sum_{i=1}^{N}\left|\operatorname{Ln}(Q)_{i_{\text {observed }}}-\operatorname{Ln}(Q)_{i_{\text {predicted }}}\right|, \quad(17)
\end{aligned}
$$

where $N$ is the number of elements in the series.

The parameters of the ABC algorithms were set to the same values for all models: colony size $(\mathrm{NP})=$ 200 , number of food sources $(\mathrm{SN})=100$, limit $=700$ 800 , and the maximum number of cycles was $\mathrm{MCN}=$ 3,000 . On the other hand, control parameters of TLBO were adjusted as follows: number of maximum iteration $(\mathrm{NMI})=50,000$ and size of population $(\mathrm{SP})=50$. Both TLBO and ABC parameters' ranges were set between $[-5,5]$. After setting control parameters, thirty independent runs were performed using TLBO and 
Table 4. Control parameter settings and convergence values.

\begin{tabular}{|c|c|c|c|c|c|c|}
\hline \multicolumn{7}{|c|}{ Control parameter settings } \\
\hline \multicolumn{6}{|c|}{ ABC parameters } & TLBO parameteı \\
\hline \multicolumn{2}{|c|}{ Colony size (NP) } & $\mathrm{SN}(\mathrm{NP} / 2)$ & $\mathrm{MCN}$ & \multicolumn{2}{|c|}{ Limit range } & $\mathrm{SP}$ \\
\hline \multicolumn{2}{|c|}{200} & 100 & 3000 & $700-800$ & & 50 \\
\hline \multicolumn{7}{|c|}{ Convergence values } \\
\hline & \multicolumn{2}{|c|}{ Linear function } & \multicolumn{2}{|c|}{ Power function } & \multicolumn{2}{|c|}{ Exponential function } \\
\hline & $\mathbf{A B C}$ & TLBO & $\mathrm{ABC}$ & TLBO & $\mathrm{ABC}$ & TLBO \\
\hline$Q_{5}$ & 0.1088 & 0.1053 & 0.1453 & 0.1285 & 0.1165 & 0.1009 \\
\hline$Q_{10}$ & 0.1445 & 0.1301 & 0.1835 & 0.1668 & 0.1587 & 0.1297 \\
\hline$Q_{25}$ & 0.2278 & 0.1807 & 0.2464 & 0.2384 & 0.2408 & 0.1839 \\
\hline$Q_{50}$ & 0.2546 & 0.2508 & 0.3048 & 0.2886 & 0.3004 & 0.2454 \\
\hline$Q_{100}$ & 0.3697 & 0.3302 & 0.4008 & 0.3703 & 0.3986 & 0.3386 \\
\hline$Q_{500}$ & 0.6107 & 0.5656 & 0.5678 & 0.5539 & 0.6645 & 0.5873 \\
\hline
\end{tabular}

ABC algorithms for each of dimensional and nondimensional regression equations. Table 4 provides control parameters and convergence values used in $\mathrm{ABC}$ and TLBO algorithms.

\section{Results and discussion}

Homogeneity of the region was determined by discordancy measure $\left(D_{i}\right)$ and heterogeneity measure $\left(H_{i}\right)$ tests based on L-moments. As a result of these tests, five of the stations which failed to pass the homogeneity criteria were extracted from consideration. The rest of 33 stations indicated that the region was homogeneous. There was no site identifying that $D_{i}$ value exceeded the critical value of $D_{c r}=3$ in these 33 stations. The region was also considered homogeneous according to heterogeneity measure, as $H_{1}$ (1.69) value took part between $H_{c r}$ ranging 1 to 2 .

GLO, LN, PE3, and GEV distributions were fitted with the flood data of the homogeneous region. The parameters of these distributions were estimated by L-moments approach. $Z^{\text {DIST }}$ statistics goodness of fit test expressed that the data of 33 stations fit with LN distribution for the region. Seckin et al. (2011) accepted the GEV distribution for whole Turkey according to the $Z^{\text {DIST }}$ goodness of fit test. In this study, LN distribution was approved for the EBSB. The reason for the difference may be the fact that they applied the distribution to the heterogeneous region. Based on the appropriate distributions for each site, flood discharges were estimated for return periods of $T=5,10,25,50,100$, and 500 years and represented as dependent variables for the regression analysis. $Q_{T}$ functions of the best-fit distribution were used for the estimation of quantiles related to $T$ values of $5,10,25$, 50,100 , and 500 years. Summary of the L-moments statistics and flood quantiles is presented in Tables 5 and 6 .

Table 5. Summary of L-moments statistics.

\begin{tabular}{|c|c|c|c|}
\hline \multicolumn{4}{|c|}{ Homogeneity measure } \\
\hline \multicolumn{4}{|c|}{$D_{i}$ values of 33 stations are between $0.14-2.85<D_{\mathrm{cr}}=3\left(D_{i}\right.$ criteria by Hosking 1994$)$} \\
\hline \multicolumn{4}{|c|}{ Heterogeneity measure } \\
\hline \multicolumn{4}{|c|}{$\begin{array}{c}\text { The region is possibly homogeneous } \\
1<H_{i}<2\left(H_{i} \text { criteria by Hosking } 1994\right)\end{array}$} \\
\hline \multicolumn{4}{|c|}{ Values of $Z^{\text {DIST }}$ statistic of various distributions } \\
\hline Distributions & L-kurtosis & $Z^{\text {DIST }}$ & \\
\hline Log Normal (LN) & 0.239 & -0.33 & $\begin{array}{l}\text { Absolute Z-statistics value } \\
\text { sufficiently closer to zero is the } 0.33\end{array}$ \\
\hline Gen. Extreme Value (GEV) & 0.212 & -1.72 & with Ln distribution \\
\hline Gen. logistik (GLO) & 0.191 & -2.78 & (Z-statistics criteria by \\
\hline Pearson tip III (PE3) & 0.156 & -4.59 & Hosking 1994) \\
\hline
\end{tabular}


Table 6. Summary statistics of flood quantiles as dependent variables.

\begin{tabular}{lccc}
\hline Flood quantile & Range & Mean & Standard deviation \\
\hline$Q_{5}\left(\mathrm{~m}^{3} / \mathrm{s}\right)$ & $24.1-449.57$ & 126.75 & 89.00 \\
$Q_{10}\left(\mathrm{~m}^{3} / \mathrm{s}\right)$ & $28.59-523.98$ & 159.05 & 107.69 \\
$Q_{20}\left(\mathrm{~m}^{3} / \mathrm{s}\right)$ & $34.44-613.63$ & 206.20 & 133.57 \\
$Q_{50}\left(\mathrm{~m}^{3} / \mathrm{s}\right)$ & $38.92-678.53$ & 246.54 & 155.36 \\
$Q_{100}\left(\mathrm{~m}^{3} / \mathrm{s}\right)$ & $43.52-741.43$ & 291.75 & 180.54 \\
$Q_{500}\left(\mathrm{~m}^{3} / \mathrm{s}\right)$ & $54.8-1037.93$ & 422.09 & 260.84 \\
\hline
\end{tabular}

For developing the regional flood-prediction equations, the relation of the flood quantiles of selected intervals and basin characteristics was determined by non-linear RA. 16 models expected to be significant were developed for six variables. LP, PF, and EF were used in the non-linear RA. The results of different combinations showed that drainage area and rainfall intensity were the variables with the most significant influence on the performance of the model. $R^{2}$ values appeared to significantly decrease as the quantiles increased in all of 16 models as expected. This approach showed that the development of non-regression model using different independent variables leads to efficient models of different flood quantiles for the range of 5 to 500 years. On the basis of this assumption, MRE, RMSE, and MAE values were applied to Model 16 to evaluate the performance of regression analysis. In order to compare them with RA, the ABC and TLBO models were also developed for Model 16.

Similarly, six independent variables were related to flood quantiles and three functions were adapted to the model. The coefficients obtained from the ABC and TLBO are presented in Tables 7 and 8, respectively. Results of the analysis with $\mathrm{RA}, \mathrm{ABC}$, and TLBO were compared in terms of the MRE, MAE, and RMSE, as given in Table 9. Among all of the error values of different return periods, the smallest one was obtained through the exponential function for $Q_{5}$ with the TLBO model as 23.42 (MAE) as marked in bold in Table 9 .

As shown in the table, the analysis showed a reasonable performance, and the comparison with each other showed that results of the TLBO and ABC were superior to those of RA. Furthermore, when compared the $\mathrm{ABC}$ with TLBO, TLBO model outperformed ABC model in terms of RMSE values for all functions, while $\mathrm{ABC}$ presented better results in terms of $\mathrm{RE}$ values, except for exponential function. There were no significant difference observed between TLBO and $\mathrm{ABC}$ in terms of MAE values for the three functions. TLBO-EF was performed as the best model with the $\mathrm{MRE}=26.87, \mathrm{MAE}=23.42$, and RMSE $=29.41$.

When they were generally considered for each return period ( $T=5,10,25,50,100$, and 500), MRE, RMSE, and MAE error values indicated that TLBO method gave better results for the estimation of flood

Table 7. Coefficients obtained from ABC.

\begin{tabular}{|c|c|c|c|c|c|c|c|c|}
\hline & \multicolumn{8}{|c|}{ Coefficients } \\
\hline & $w_{0}$ & $w_{1}$ & $w_{2}$ & $w_{3}$ & $w_{4}$ & $w_{5}$ & $w_{6}$ & $w_{7}$ \\
\hline & \multicolumn{8}{|c|}{$y_{\text {linear }}=w_{0}+w_{1} x_{1}+w_{2} x_{2}+w_{3} x_{3}+w_{4} x_{4}+w_{5} x_{5}+w_{6} x_{6}$} \\
\hline$Q_{5}$ & 0.0013 & 0.9281 & 0.0138 & -0.0728 & -0.1191 & 0.3003 & 0.0728 & - \\
\hline$Q_{10}$ & -0.039 & 0.9652 & 0.0536 & -0.0342 & -0.106 & 0.3987 & 0.0384 & - \\
\hline$Q_{25}$ & 0.057 & 1.008 & -0.0413 & -0.1462 & -0.1854 & 0.4126 & 0.0072 & - \\
\hline$Q_{50}$ & -0.0203 & 1.016 & 0.0912 & 0.0096 & -0.1721 & 0.3185 & 0.1533 & - \\
\hline$Q_{100}$ & -0.076 & 1.0788 & 0.16 & 0.0343 & -0.1521 & 0.3489 & 0.1963 & - \\
\hline \multirow[t]{2}{*}{$Q_{500}$} & -0.0538 & 0.9677 & 0.2788 & 0.0773 & -0.2028 & 0.1145 & 0.381 & - \\
\hline & \multicolumn{8}{|c|}{$y_{\text {power }}=w_{0} x_{1}^{w_{1}} x_{2}^{w_{2}} x_{3}^{w_{3}} x_{4}^{w_{4}} x_{5}^{w_{5}} x_{6}^{w_{6}}$} \\
\hline$Q_{5}$ & 3.0383 & 1.0011 & 0.0077 & 0.0928 & -0.1745 & 0.728 & -0.033 & - \\
\hline$Q_{10}$ & 2.9856 & 1.0187 & 0.0359 & 0.0882 & -0.2043 & 0.4263 & 0.2173 & - \\
\hline$Q_{25}$ & 3.9857 & 1.0245 & 0.1402 & 0.1707 & -0.2576 & 0.2357 & 0.4237 & - \\
\hline$Q_{50}$ & 3.2846 & 0.989 & 0.105 & 0.1622 & -0.3203 & 0.0508 & 0.5546 & - \\
\hline$Q_{100}$ & 2.2542 & 0.8708 & 0.0046 & 0.2208 & -0.4241 & -0.096 & 0.5833 & - \\
\hline \multirow[t]{2}{*}{$Q_{500}$} & 2.8765 & 0.7379 & 0.2109 & 0.2558 & -0.3612 & -0.1302 & 0.6105 & - \\
\hline & \multicolumn{8}{|c|}{$y_{\text {exponential }}=w_{0}+\exp \left(w_{1}+w_{2} x_{1}+w_{3} x_{2}+w_{4} x_{3}+w_{5} x_{4}+w_{6} x_{5}+w_{7} x_{6}\right)$} \\
\hline$Q_{5}$ & -0.3094 & -1.0171 & 1.2824 & 0.0011 & -0.0232 & -0.16 & 0.3408 & 0.3076 \\
\hline$Q_{10}$ & -0.5406 & -0.5813 & 1.0105 & 0.0438 & -0.0208 & -0.0989 & 0.1751 & 0.3021 \\
\hline$Q_{25}$ & -1.0501 & -0.0072 & 0.7229 & 0.0751 & 0.0091 & -0.0644 & 0.1124 & 0.2512 \\
\hline$Q_{50}$ & -0.5823 & -0.5284 & 0.9689 & 0.1548 & 0.0342 & -0.1434 & 0.067 & 0.443 \\
\hline$Q_{100}$ & -0.0937 & -1.1584 & 1.3921 & -0.0859 & 0.2376 & -0.6509 & 0.044 & 0.6473 \\
\hline$Q_{500}$ & -0.3793 & -0.7914 & 1.0202 & 0.2534 & 0.1178 & -0.2271 & -0.0615 & 0.6863 \\
\hline
\end{tabular}


Table 8. Coefficients obtained from TLBO.

\begin{tabular}{|c|c|c|c|c|c|c|c|c|}
\hline & \multicolumn{8}{|c|}{ Coefficients } \\
\hline & $w_{0}$ & $w_{1}$ & $w_{2}$ & $w_{3}$ & $\boldsymbol{w}_{4}$ & $w_{5}$ & $w_{6}$ & $w_{7}$ \\
\hline & \multicolumn{8}{|c|}{$y_{\text {linear }}=w_{0}+w_{1} x_{1}+w_{2} x_{2}+w_{3} x_{3}+w_{4} x_{4}+w_{5} x_{5}+w_{6} x_{6}$} \\
\hline$Q_{5}$ & 0.0502 & 0.892 & -0.0211 & -0.0552 & -0.1493 & 0.2647 & 0.0691 & - \\
\hline$Q_{10}$ & 0.0586 & 0.9079 & -0.0199 & -0.0288 & -0.1701 & 0.2586 & 0.0926 & - \\
\hline$Q_{25}$ & 0.069 & 0.9299 & -0.0012 & 0.0017 & -0.2024 & 0.2204 & 0.1461 & - \\
\hline$Q_{50}$ & 0.0344 & 1.0212 & 0.047 & -0.048 & -0.2048 & 0.3196 & 0.1221 & - \\
\hline$Q_{100}$ & 0.0943 & 0.9632 & 0.0438 & 0.0493 & -0.2639 & 0.1217 & 0.2669 & - \\
\hline \multirow[t]{2}{*}{$Q_{500}$} & 0.1502 & 0.8286 & 0.0993 & 0.0913 & -0.3031 & -0.0092 & 0.3471 & - \\
\hline & \multicolumn{8}{|c|}{$y_{\text {power }}=w_{0} x_{1}^{w_{1}} x_{2}^{w_{2}} x_{3}^{w_{3}} x_{4}^{w_{4}} x_{5}^{w_{5}} x_{6}^{w_{6}}$} \\
\hline$Q_{5}$ & 1.977 & 0.8727 & 0.0254 & 0.0822 & -0.2283 & 0.4945 & 0.0142 & - \\
\hline$Q_{10}$ & 2.1365 & 0.8595 & 0.0464 & 0.1032 & -0.2396 & 0.4274 & 0.0825 & - \\
\hline$Q_{25}$ & 3.3168 & 0.9848 & 0.1099 & 0.1106 & -0.2273 & 0.2911 & 0.3282 & - \\
\hline$Q_{50}$ & 2.9393 & 0.8793 & 0.1563 & 0.1627 & -0.2873 & 0.169 & 0.3608 & - \\
\hline$Q_{100}$ & 2.9461 & 0.8518 & 0.1389 & 0.1831 & -0.3157 & 0.0668 & 0.4581 & - \\
\hline \multirow[t]{2}{*}{$Q_{500}$} & 3.4762 & 0.7869 & 0.2724 & 0.1933 & -0.279 & -0.1048 & 0.6151 & - \\
\hline & \multicolumn{8}{|c|}{$y_{\text {exponential }}=w_{0}+\exp \left(w_{1}+w_{2} x_{1}+w_{3} x_{2}+w_{4} x_{3}+w_{5} x_{4}+w_{6} x_{5}+w_{7} x_{6}\right)$} \\
\hline$Q_{5}$ & -0.7275 & -0.1863 & 0.7551 & -0.0579 & -0.0281 & -0.1509 & 0.2435 & 0.0692 \\
\hline$Q_{10}$ & -1.1919 & 0.2549 & 0.5428 & -0.0294 & -0.0086 & -0.1169 & 0.1595 & 0.067 \\
\hline$Q_{25}$ & -2.3066 & 0.8731 & 0.3298 & -0.0047 & 0.0054 & -0.0783 & 0.084 & 0.0571 \\
\hline$Q_{50}$ & -2.6204 & 0.9993 & 0.2969 & 0.0048 & 0.0138 & -0.0761 & 0.0527 & 0.0722 \\
\hline$Q_{100}$ & -3.0389 & 1.1457 & 0.2683 & 0.0116 & 0.0184 & -0.0762 & 0.0333 & 0.0809 \\
\hline$Q_{500}$ & -1.8907 & 0.7184 & 0.3326 & 0.0492 & 0.0523 & -0.142 & -0.0227 & 0.1714 \\
\hline
\end{tabular}

Table 9. MRE, MAE, and RMSE values.

\begin{tabular}{|c|c|c|c|c|c|c|c|c|c|}
\hline \multicolumn{10}{|c|}{ Regression Analysis (RA) } \\
\hline & \multicolumn{3}{|c|}{ Linear function } & \multicolumn{3}{|c|}{ Power function } & \multicolumn{3}{|c|}{ Exponential function } \\
\hline & MRE & MAE & RMSE & MRE & MAE & RMSE & MRE & MAE & RMSE \\
\hline$Q_{5}$ & 25.54 & 24.54 & 30.0 & 30.48 & 29.74 & 38.5 & 33.34 & 26.14 & 31.9 \\
\hline$Q_{10}$ & 26.90 & 31.38 & 38.9 & 33.14 & 39.75 & 50.9 & 35.26 & 35.40 & 42.9 \\
\hline$Q_{25}$ & 29.64 & 43.08 & 53.6 & 36.31 & 54.94 & 69.5 & 37.90 & 49.82 & 60.6 \\
\hline$Q_{50}$ & 32.75 & 55.87 & 68.1 & 38.73 & 68.28 & 85.9 & 39.81 & 62.05 & 77.3 \\
\hline$Q_{100}$ & 36.18 & 70.82 & 87.3 & 41.56 & 83.90 & 105.1 & 42.62 & 77.25 & 98.4 \\
\hline$Q_{500}$ & 47.88 & 126.14 & 160.9 & 46.05 & 145.56 & 178.5 & 53.34 & 130.01 & 175.7 \\
\hline \multicolumn{10}{|c|}{ Artificial Bee Colony Algorithms (ABC) } \\
\hline & \multicolumn{3}{|c|}{ Linear function } & \multicolumn{3}{|c|}{ Power function } & \multicolumn{3}{|c|}{ Exponential function } \\
\hline & MRE & MAE & RMSE & MRE & MAE & RMSE & MRE & MAE & RMSE \\
\hline$Q_{5}$ & 23.92 & 24.25 & 30.53 & 23.72 & 26.98 & 35.29 & 27.36 & 24.96 & 31.6 \\
\hline$Q_{10}$ & 25.17 & 31.57 & 40.98 & 23.7 & 34 & 46.18 & 27.47 & 33.03 & 42.94 \\
\hline$Q_{25}$ & 24.67 & 46.49 & 60.15 & 27.88 & 47.81 & 62.55 & 30.57 & 48.39 & 61.84 \\
\hline$Q_{50}$ & 29.72 & 54.54 & 70.22 & 30.27 & 57.71 & 76.84 & 33.09 & 58.34 & 76.28 \\
\hline$Q_{100}$ & 33.77 & 72.2 & 92.34 & 33.61 & 73.07 & 96.14 & 37.99 & 74.02 & 95.88 \\
\hline$Q_{500}$ & 45.41 & 126.84 & 167.17 & 44.71 & 126.86 & 161.2 & 44.94 & 123.9 & 174.38 \\
\hline \multicolumn{10}{|c|}{ Teaching-Learning Based Optimization (TLBO) } \\
\hline & \multicolumn{3}{|c|}{ Linear function } & \multicolumn{3}{|c|}{ Power function } & \multicolumn{3}{|c|}{ Exponential function } \\
\hline & MRE & MAE & RMSE & MRE & MAE & RMSE & MRE & MAE & RMSE \\
\hline$Q_{5}$ & 25.43 & 24.42 & 30.04 & 26.97 & 26.33 & 33.19 & 26.87 & 23.42 & 29.41 \\
\hline$Q_{10}$ & 26.90 & 31.39 & 38.88 & 29.24 & 35.07 & 44.02 & 27.36 & 30.56 & 38.81 \\
\hline$Q_{25}$ & 29.64 & 43.08 & 53.58 & 27.96 & 46.29 & 61.53 & 29.54 & 43.59 & 54.04 \\
\hline$Q_{50}$ & 29.46 & 55.23 & 69.70 & 31.69 & 57.23 & 74.77 & 32.60 & 56.07 & 68.94 \\
\hline$Q_{100}$ & 36.18 & 70.82 & 87.27 & 34.25 & 70.35 & 92.41 & 35.84 & 71.08 & 88.37 \\
\hline$Q_{500}$ & 47.89 & 126.15 & 160.89 & 47.01 & 127.27 & 159.21 & 46.31 & 125.04 & 163.95 \\
\hline
\end{tabular}


Table 10. Best equations for $Q_{5}, Q_{10}, Q_{25}, Q_{50}, Q_{100}$, and $Q_{500}$.

\begin{tabular}{cccc}
\hline$Q_{\boldsymbol{T}}$ & Method & Func. & Equation \\
\hline$Q_{5}$ & TLBO & Exp. & $y=-0.7275+\exp \left(-0.1863+0.7551 x_{1}-0.0579 x_{2}-0.0281 x_{3}-0.1509 x_{4}+0.2435 x_{5}\right.$ \\
& & & $\left.+0.0692 x_{6}\right)$ \\
$Q_{10}$ & TLBO & Exp. & $y=-1.1919+\exp \left(0.2549+0.5428 x_{1}-0.0294 x_{2}-0.0086 x_{3}-0.1169 x_{4}+0.1595 x_{5}\right.$ \\
& & & $\left.+0.067 x_{6}\right)$
\end{tabular}

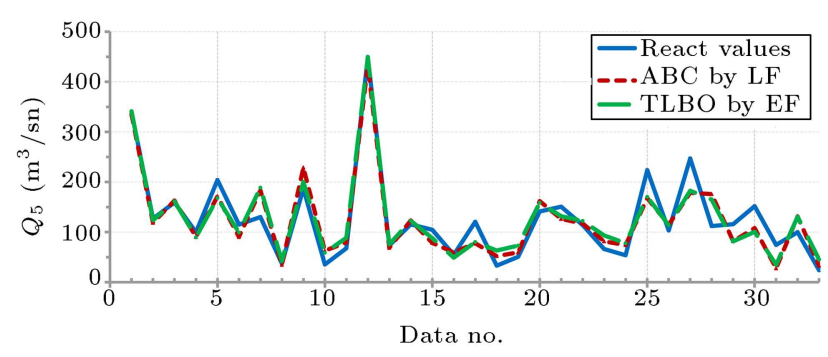

Figure 2. The best functions in terms of comparison of $\mathrm{ABC}$ and TLBO for $Q_{5}$.

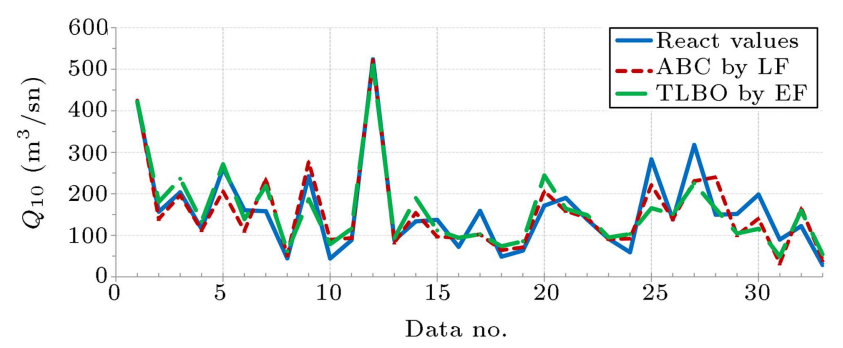

Figure 3. The best functions in terms of comparison of $\mathrm{ABC}$ and TLBO for $Q_{10}$.

quantiles for different independent variables. The best-fit equations for $Q_{5}, Q_{10}, Q_{25}, Q_{50}, Q_{100}$, and $Q_{500}$ obtained with the ABC and TLBO models are given in Table 10. Figures 2-7 also show the best functions in terms of comparison of ABC and TLBO.

\section{Conclusion}

The paper presents the application of the regression analysis, along with ABC and TLBO models to RFFA based on L-moments for the EBSB, Turkey. Based

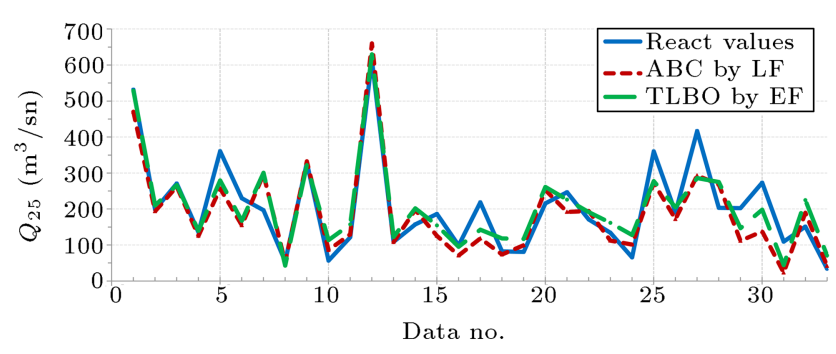

Figure 4. The best functions in terms of comparison of $\mathrm{ABC}$ and TLBO for $Q_{25}$.

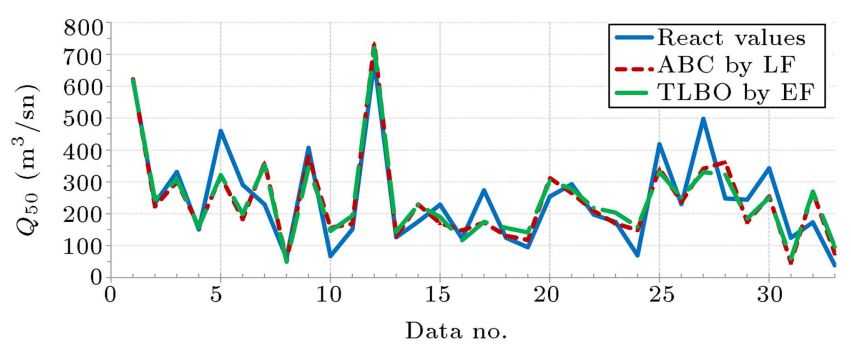

Figure 5. The best functions in terms of comparison of $\mathrm{ABC}$ and TLBO for $Q_{50}$.

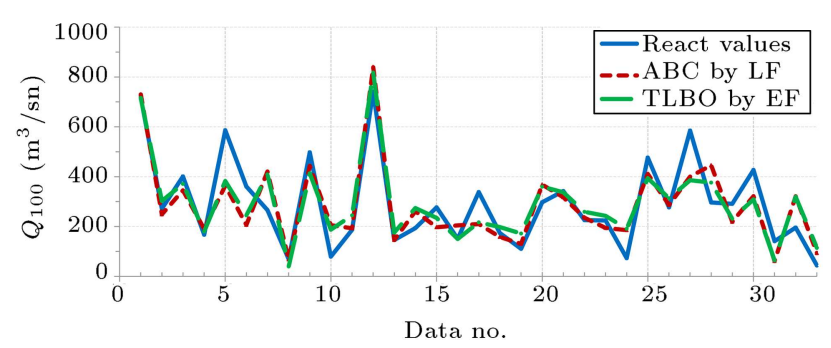

Figure 6. The best functions in terms of comparison of $\mathrm{ABC}$ and TLBO for $Q_{100}$. 


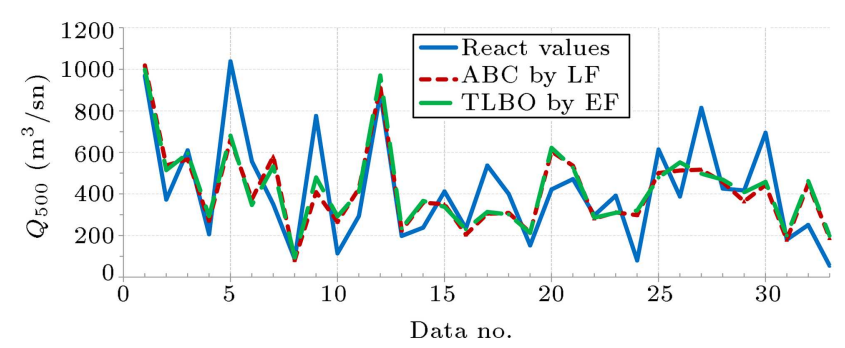

Figure 7. The best functions in terms of comparison of ABC and TLBO for $Q_{500}$.

on the L-moments approach, flood quantiles were estimated for return periods of $T=5,10,25,50,100$, and 500 years. Moreover, these quantiles were used as dependent variables in the analysis. It has been found that Model 16, including the independent variables of drainage area, mainstream slope, mean annual rainfall, stream density, elevation, and rainfall intensity, outperforms other models with different combinations in terms of higher $R^{2}$ values. It has also been found that the choice of inputting independent variables to the model has a significant impact on the estimation of discharges. For developing the regional flood-prediction equations, the relation of the flood quantiles of selected intervals and basin characteristics was determined by non-linear RA. In order to evaluate the performance of the RA in comparison with those of the $\mathrm{ABC}$ and TLBO methods, MRE, RMSE, and MAE measures were applied to the model. The results indicated that the TLBO and ABC outperformed the RA. TLBOEF was performed as the best model with the MRE $=26.87$, $\mathrm{MAE}=23.42$, and RMSE $=29.41$. The results also further suggest that TLBO is superior to the ABC. The proposed equations obtained using the $\mathrm{ABC}$ and TLBO algorithms successfully estimate the flood quantile parameters. As the results of the TLBO algorithm were found to be satisfactory in this study, the use of the ABC and TLBO algorithm in hydrology is encouraged and recommended for future studies.

\section{Acknowledgements}

This paper is dedicated to the memory of the late Associate Professor Dr. Murat İhsan Kömürcü, who passed away in February 2013.

\section{References}

1. Anilan, T., Satılmıs, U., Kankal, M., and Yuksek, O. "Application of artificial neural networks and regression analysis to L-moments based regional frequency analysis in the Eastern Black Sea Basin, Turkey", KSCE J. Civ. Eng., 20(5), pp. 2082-2092 (2016).

2. Jiapeng, H., Liang, Z., and Yu, Z. "A modified rational formula for flood design in small basins", Journal of American Water Resources Association, 39(5), pp. 1017-1025 (2003).
3. Wallis, J.R. Risk and Uncertainties in the Evaluation of Flood Events for the Design of Hydraulic Structures, In Piene e Siccit, edited by E. Guggino, G. Rossi, E. Todini, pp. 3-36. Fondazione Politecnica del Mediterraneo, Catania, Italy (1982).

4. Landwehr, J.M., Matalas, N.C., and Wallis, J.R. "Probability-weighted moments compared with some traditional techniques in estimating gumbel parameters and quantiles", Water Resour. Res., 15, pp. 10551064 (1979).

5. Hosking, J.R.M. "L-Moments: Analysis and estimation of distributions using linear combinations of order statistics", Journal of the Royal Statistical Society Series, B 52, pp. 105-124 (1990).

6. Rao, A.R. and Hamed, K.H. "Regional frequency analysis of Wabash River flood data by L-moments", J. Hydrol. Eng., 2(4), pp. 169-179 (1997).

7. Parida, B.P., Kachroo, R.K., and Shrestha, D.B. "Regional flood frequency analysis of Mahi-Sabarmati Basin using index flood procedure with L-moments", Water Resour. Manag., 12, pp. 1-12 (1998).

8. Adamowski, K. "Regional analysis of annual maximum and partial duration flood data by nonparametric and L-moment methods", J. Hydrol., 229, pp. 219-231 (2000).

9. Haktanir, T. "Comparison of various flood frequency distributions using annual flood peaks data of rivers in Anatolia", J. Hydrol., 136 (1-4), pp. 1-31 (1992).

10. Sorman, U. and Okur, A. "Application of at site and regional frequency analyses by using the L-moments technique", IMO Digest., 11(3), pp. 665-668 (2000).

11. Atiem, A. and Harmanıcoglu, N.B. "Assessment of regional floods using L-moments approach: the case of the River Nile", Water Resour Manag., 20(5), pp. 723-747 (2006).

12. Saf, B. "Regional flood frequency analysis using Lmoments for the Buyuk and Kucuk Menderes River Basins of Turkey", J. Hydrol. Eng., 14(8), pp. 783-794 (2009).

13. Bayazit, M. and Onoz, B. "LL-moments for estimating low flow quantiles", Hydrolog. Sci. J., 47(5), pp. 707702 (2009).

14. Seckin, N., Cobaner, M., Yurtal, R., and Haktanir, T. "Comparison of ANN methods with L-moments for estimating flood flow at ungauged sites: The Case of East Mediterranean River Basin, Turkey", Water Resour. Manag., 27, pp. 2103-2124 (2013).

15. Aydogan, D., Kankal, M., and Onsoy, H. "Regional flood frequency analysis for Coruh Basin of Turkey with L-moments approach", J. Flood Risk Manage., 9, pp. 69-86 (2016).

16. Firat, M., Koc, A.C., Dikbas, F., and Gungor, M. "Identification of homogeneous regions and regional frequency analysis for Turkey", Sci. Iran., Transaction A, Civil Engineering, 21(5), pp. 1492-1502 (2014). 
17. Fill, H.D. and Stedinger, J.R. "Using regional regression within index flood procedures and an empirical Bayesian estimator", J. Hydrol., 210, pp. 128-145, (1998).

18. Pandey, G.R. and Nguyen, V.T.V. "A comparative study of regression based methods in regional flood frequency analysis", J. Hydrol., 225, pp. 92-101 (1999).

19. Ouarda, T.B.M.J., Girard, C., Cavadias, G.S., and Bobee, B. "Regional flood frequency estimation with canonical correlation analysis", J. Hydrol., 254, pp. 157-173 (2001).

20. Jingy, I.Z. and Hall, M.J. "Regional flood frequency analysis for the Gan-Ming River Basin in China", $J$. Hydrol., 296, pp. 98-117 (2004).

21. Reis, J.R., D.S., Stedinger, J.R., and Martins, E.S. "Bayesian GLS regression with application to LPE3 regional skew estimation", Water Resour Res., 41, W10419 (2005). DOI: 10.1029/ 2004WR00344

22. Rahman, A. "A quantile regression technique to estimate design floods for ungauged catchments in south-east Australia", Australian Journal of Water Resources, 9(1), pp. 81-89 (2005).

23. Griffis, V.W. and Stedinger, J.R. "The use of GLS regression in regional hydrologic analysis", J. Hydrol., 344, pp. 82-95 (2007).

24. Leclerc, M. and Ouarda, T.B.M.J. "Non stationary regional frequency analysis at ungaged sites", J. Hydrol., 343, pp. 254-265 (2007).

25. Haddad, Kh., Rahman, A., Weinmann, P.E., Kuczera, G., and Ball, J. "Streamflow data preparation for regional flood frequency analysis: Lessons from southeast Australia", Australian Journal of Water Resources, 14(1), pp. 17-32 (2010).

26. Palmen, L.B. and Weeks, W.D. "Regional flood frequency for Queesland using the quantile regression technique", Australian Journal of Water Resources, 15(1), pp. 47-56 (2011).

27. Rahman, A., Haddad, K., Zaman, M., Kuczera, G., and Weinmann, P.E. "Design flood estimation in ungauged catchments: a comparison between the probabilistic rational method and quantile regression technique for NSW", Australian Journal of Water Resources, 14(2), pp. 127-137 (2011).

28. Malekinezhad, H., Nactnebel, H.D., and Klik, A. "Comparing the index flood and multiple regression methods using L-moments", Phys. Chem. Earth, 36, pp. 54-60 (2011).

29. Haddad, K. and Rahman, A. "Regional flood frequency analysis in Eastern Australia: Bayesian GLS regression-based methods within fixed region and ROI framework-quantile regression and parameter regression technique", J. Hydrol., 430-431, pp. 142-161 (2012).

30. Zaman, M.A., Rahman, A., and Haddad, K. "Regional flood frequency analysis in arid regions: A case study for Australia", J. Hydrol., 475, pp. 74-83 (2012).
31. Rezaeianzadeh, M., Tabari, H., Yazdi, A.A., Isik, S., and Kalin, L. "Flood flow forecasting using ANN, ANFIS and regression models", Neural Comput. Appl., 25(1), pp. 25-37 (2014).

32. Shu, C. and Burn, D.H. "Homogeneous pooling group delineation for flood frequency analysis using a fuzzy expert system with genetic enhancement", J. Hydrol., 291, pp. 132-149 (2004).

33. Dawson, C.W., Abrahart, R.J., Shamseldin, A.Y., and Wilby, R.L "Flood estimation at ungauged sites using artificial neural networks", J. Hydrol., 319, pp. 391409 (2006).

34. Shu, C. and Ouarda, T.B.M.J "Flood frequency analysis at ungauged sites using ANN in canonical correlation analysis physiographic space" Water Resour Res., 43, W07438 (2007). DOI: 10.1029/2006WR005142

35. Shu, C. and Ouarda, T.B.M.J "Regional flood frequency analysis at ungauged sites using the adaptive neuro-fuzzy inference system", J. Hydrol., 349, pp. 3143 (2008).

36. Aziz, K., Rahman, A., Fang, G., and Shrestha, S. "Application of artificial neural networks in regional flood frequency analysis: a case study for Australia", Stoch. Env. Res. Risk A., 28(3), pp. 541-554 (2014).

37. Chau, K.W. "Particle swarm optimization training algorithm for ANNs in stage prediction of Shing Mun River", J. Hydrol., 329, pp. 363-367 (2006).

38. Jiong-feng, C., and Wan-chang, Z. "Application of genetic algorithm for model parameter calibration in daily rainfall-runoff simulations with the Xinanjiang model", Journal of China Hydrology, 26(4), pp. 32-38 (2006).

39. Jun, Z., Chuntian, C., Jianjian, S., and Shiqin, Z. "Ant colony optimization-based support-vector machine for mid-and-long term hydrological forecasting", Journal of Hydroelectric Engineering, 06 (2010).

40. Kisi, O., Ozkan, C., and Akay, B. "Modeling dischargesediment relationship using neural networks with artificial bee colony algorithm", J. Hydrol., 428-429, pp. 94-103 (2012).

41. Salimi, S., Mahmoodi, H., and Barahman, N. "Weeklydischarge estimation for Tang-Karzin's station, using MLP network optimized by $\mathrm{ABC}$ algorithm" International Journal of Basic and Applied Science, 02(02), pp. 242-253 (2013).

42. Uzlu, E., Kankal, M., Akpinar, A., and Dede, T. "Estimates of energy consumption in Turkey using neural networks with the teaching-learning-based optimization algorithm." Energy, 75, pp. 295-303 (2014).

43. Yerdelen, C. "Change point of river stream ow in Turkey." Sci. Iran., Transaction A, Civil Engineering, 21(2), p. 306 (2014).

44. Yuksek, O., Kankal, M., and Ucuncu, O. "Assessment of big floods in the Eastern Black Sea Basin of Turkey" Environmental Monit Assess, 185, pp. 797-814 (2013). 
45. DMi, Analysis of Turkey's Maximum Precipitation Values and their Return Periods, Ankara, Turkey: Turkish State Meteorological Service (2001).

46. DSi "Annual flood reports" Ankara, Turkey, General Directorate of State Hydraulic Works (1970-2005).

47. Saka, F. "Determination of synthetic flow duration curves by using mathematical methods and a case study in the Eastern Black Sea" PhD Thesis, Karadeniz Technical University, Turkey (2012).

48. Yang, T., Shao, Q., Hao, Z.C., Chen, X., Zhang, Z., $\mathrm{Xu}, \mathrm{C} . Y$. , and Sun, L. "Regional frequency analysis and spatio temporal pattern characterization of rainfall extremes in Pearl River Basin, China", J. Hydrol., 380, pp. 386-405 (2010).

49. Nyeko-Ogiramoi, P., Willems, P., Mutua, F.M., and Moges, S.A. "An elusive search for regional flood frequency estimates in the River Nile Basin", Hydrology and Earth System Sciences, 16, pp. 3149-3163 (2012).

50. Hosking, J.R.M. "On the characterization of distributions by their L-moments", Journal of Statistical Planning and Inference, 136, pp. 193-198 (2004).

51. Hosking, J.R.M. L-Moments, John Wiley \& Sons, Inc. (1998).

52. Anilan, T. "Application of artificial intelligence methods to L-moments based regional frequency analysis in the Eastern Black Sea Basin", PhD Thesis, Karadeniz Technical University, Turkey (2014).

53. Karaboga, D. "An idea based on honey bee swarm for numerical optimization", Technical Report- TR06, Erciyes University Engineering Faculty of Computer Engineering Department (2005).

54. Oztürk, H.T. and Durmus, A. "Optimum cost design of RC columns using artificial bee colony algorithm", Struct. Eng. Mech., 45(5), pp. 643-54 (2013).

55. Pan, Q.K., Tasgetiren, M.F., Suganthan, P.N., and Chua, T.J. "A discrete artificial bee colony algorithm for the lot-streaming flow shop scheduling problem", Inf. Sci., 181, pp. 2455-60 (2011).

56. Karaboga, D. and Basturk, B. "Artificial bee colony (ABC) optimization algorithm for solving constrained optimization problems", Found Fuzzy Log Soft Comput, 4529, pp. 789-798 (2007).

57. Uzlu, E., Akpınar, A., Ozturk, H.T., Nacar, S., and Kankal, M. "Estimates of hydroelectric generation using neural networks with ABC algorithm for Turkey", Energy, 69, pp. 638-647 (2014).

58. Rao, R.V., Savsani, V.J., and Vakharia, D.P. "Teaching-learning based optimization: A novel method for constrained mechanical design optimization problems", Computer-Aided Design, 43, pp. 303315 (2011).

59. Togan, V. "Design of planar steel frames using teaching-learning based optimization", Eng. Struct., 34, pp. 225-32 (2012).

60. Togan, V. "Design of pin jointed structures using teaching learning based optimization", Struct. Eng. Mech., 47, pp. 209-225 (2013).

61. Dede, T. "Optimum design of grillage structures to LRFD-AISC with teaching-learning based optimization", Structural and Multidisciplinary Optimization, 48, pp. 955-964 (2013).

\section{Biographies}

Tuğçe Anılan is an Assistant Professor in Civil Engineering Department in Karadeniz Technical University, Trabzon, Turkey. Her current research focuses on flood frequency analysis, floods and sea outfalls.

Ergun Uzlu received BS, MS, and PhD degrees in Civil Engineering from Karadeniz Technical University, Trabzon, Turkey in 2008, 2011, and 2016, respectively. $\mathrm{He}$ is currently a Research Assistant in Karadeniz Technical University, Trabzon, Turkey. His research interests include coastal engineering, energy estimate models, and artificial intelligence techniques.

Murat Kankal is an Assistant Professor in Civil Engineering Department in Karadeniz Technical University, Trabzon, Turkey. His current research focuses on sediment transport in coastal area, regional flood frequency analysis, hydropower, and artificial neural networks.

Ömer Yüksek was born in Çaykara, Trabzon, Turkey in 1962. He graduated from Maraşı Village Primary School, from Çaykara İnönü Secondary School, from Trabzon Religious Vocational High School, and from Karadeniz Technical University (KTU) Engineering Faculty (EF) at Civil Engineering Department (CED). He completed Post Graduate and Doctorate Educations in KTU CED Hydraulic Division (HD) in 1986 and 1992, respectively. He studied in KTU EF CED HD as a Research Assistant between 1984-1993, as an Assistant Professor between 1993-1996, as an Associate Professor between 1996-2005, and as a Professor from 2005 until now. He is the Head of Hydraulic Division. 